\title{
Design features of health information visualization for the purpose of efficacy perception about weight control among young adults: A mixed methods study
}

\author{
Xing Huang \\ Keywords. Information visualization, self-generated health information, self-efficacy
}

\section{Introduction}

We are information receivers and, at the same time, data producers. There is a profound change of how we acquire data and how we make use of them. On one hand, driven by the exponential growth of medical data (i.e., self-generated health information ${ }^{1}$, medical records, lab reports, etc.), we are able to access health-related data much easier these days than we used to. However, do these high-yield data really proffer legible information? Or are people just overwhelmed with poorly presented information to make sense of and take action to change their health behavior accordingly? As the quantity, accessibility, and complexity of medical data, improving understanding and motivation of health behavior change is not only a medical problem but also an information problem.

On the other hand, health promotion has undergone changes which shifted from scaring, rewarding, to motivating people to change and manage their health habits (Bandura, 1998, p.623). There is a need of usable and useful medical information visualization that can promote

${ }^{1}$ Self-generated health information refers to health-related data which is created, recorded, gathered or inferred by individuals themselves, which includes data from an observation, a device tracking, or a test result. It is defined based on the definition of patient-generated health-information (PCHI). (Deering, Mary Jo. (2013). Issue Brief: Patient-Generated Health Data and Health IT. The Office of the National Coordinator for Health Information Technology. Retrieved from https://www.healthit.gov/sites/default/files/pghd_brief_final122013.pdf) 
health behavior change. In addition to just educating people, Thomas Goetz in a TED Talk mentioned that there is a need of giving them a sense of efficacy to health behavior change. The term "self-efficacy" originally from Albert Bandura's words refers to "beliefs in one's capabilities to organize and execute the courses of action required to manage prospective situation" (A. Bandura, 1982). In the medical context of this study, it relates to giving people information about their health and enable them to aware of a path towards better health so that they have the belief that they can manage health habits which associated with possible health outcomes.

This study focuses on weight control since a considerable amount of the reported deaths in the United States are among lifestyle diseases, which can be manageable by changing lifestyle and controlling weight (Amber Howard, 2011, p1). Although, there are many fitness management programs have been carried out, the trends of technology, visual communication, and health care call into a question: What are the design features of health information visualization that impact on young adults" ${ }^{2}$ self-efficacy perception about weight control? In this study, the term of "health information visualization" is not data visualization in the field of statistic which deals with data analyses and visual representation tools. Instead, information visualization is a functional and aesthetic way of revealing knowledge and telling a story behind data in a way that can reinforce human cognition and be useful in our lives.

\section{Methods}

This study intends to find out the design features of health information visualization that can positively influence young adults' perception of self-efficacy about weight control. An exploratory mixed methods design has been used by firstly collecting qualitative data in order to

\footnotetext{
${ }^{2}$ Young adults refer to people in the age range of 20-39. (Retrieved from https://en.wikipedia.org/wiki/Young_adult_(psychology))
} 
develop an information visualization intervention, which then followed with a quantitative phase to assess the design features. The overall procedure is shown in figure 1.

Figure 1. Exploratory sequential mixed methods

\begin{tabular}{|c|c|c|}
\hline $\begin{array}{l}\text { PHASE } 1 \text { - QUAL } \\
\text { Open-ended interviews } \\
\text { - Health providers from N.C. } \\
\text { State University Student } \\
\text { Health Center }(n=3) \\
\text { - Health providers from } \\
\text { Peking University Health } \\
\text { Science Center ( } n=8) \\
\square \text { Open-ended survey } \\
\text { - Graduate students from } \\
\text { N.C. State University } \\
\text { (n=24) }\end{array}$ & $\begin{array}{l}\text { Design the Intervention } \\
\text { Design features } \\
\text { - Visualizing the } \\
\text { comparison of intake } \\
\text { and burn calories } \\
\text { - Showing both the } \\
\text { short-term and long- } \\
\text { term predictions } \\
\text { - Showing a path to a } \\
\text { goal }\end{array}$ & $\begin{array}{l}\text { PHASE } 2 \text { - QUAN } \\
\text { A/B test } \\
\text { (general self-efficacy scale) } \\
\text { - Graduate students from } \\
\text { N.C. State University ( } 21 \\
\text { out of } 24 \text { from phase 1) }\end{array}$ \\
\hline
\end{tabular}

In the first phase, qualitative data was collected from open-ended interviews and surveys. Eleven providers from two health centers involved in this study as convenient samples. The purpose was to explore the factors on gaining weight and the strategies of weight control, which informed the content of the health information. Data was also collected from graduate students $(n=24)$ (participants age range from 20 to36, who can represent young adults) for the same intention. The qualitative results from phase one informed design features of health information visualization which was then assessed in the quantitative phase by using A/B test survey. Twenty-one students involved in the survey and each of them has been shown 3 groups of visualized calories information. In the first group, group 1-a showed the amount of intake calories and calorie consumption by time; group 1-b added a comparison between the amount of intake and consumed calories among the original diagram. In the second group, group 2-a showed the the same diagram as in the group1-a; while in the group 2-b, there was a prediction of weight by a short-term (3 days) and a long-term (a month). In the last group, group 3-a showed the same diagram as in the group 1-a; group 3-b showed a path toward an ideal weight 
besides the original visualization. Participants are required to rate their certainty from 0 to 100 by using the general self-efficacy scale (GSE). The means of the differences between the A/B groups were calculated which estimated the function of the three design features on self-efficacy perception.

\section{Results}

Three design features were generated from the analysis of qualitative data in the phase 1: 1 . Visualizing the comparison of intake and consumed calories; 2. Showing both the short-term and long-term predictions of weight; 3 . Showing an ideal path of weight control. In the phase 2 , the means of $\mathrm{A} / \mathrm{B}$ test results among the three groups are: $\mu_{1}=5.26, \mu_{2}=9.48, \mu_{3}=7.01$. The results indicate all of the three design features have a positive influence on self-efficacy perception among young adults about weight control.

\section{Discussion}

The differences between the A/B results may be caused by other reasons besides changes of perceived self-efficacy. They could be influenced by the amount of represented information, legibility, participants' cognitive load, etc. For these reasons, future work may apply EEG for a double check. Besides, health providers from two countries may involve cultural difference which could be a limitation of this study.

\section{Conclusion}

All of the three design features which generated from this study consist with the theory in Bandura's articles which pointed out that visualizing one's success, finding a role-model, and reviewing past successes can help build high self-efficacy. If we could take the advantage of theses design features, and visualized health information in an appropriate way, young adults may take a better responsibility of taking care of his/her own health. 


\section{Acknowledgements}

Much appreciation to all the participants.

\section{Reference list}

1. Amber Kristine Howard. 2011. Feedforward: A Mobile Design Strategy that Supports Emotive Learning for Preventive Health Practices and Enduring Lifestyle Change. North Carolina State University.

2. Albert Bandura. 2006. "Guide for Constructing Self-Efficacy Scales," in Self-Efficacy Beliefs of Adolescents, 307-337. Information Age Publishing, 2006.

3. Albert Bandura. 1977. Self-efficacy: Toward a unifying theory of behavioral change. Psychological Review, 84(2), 191-215. doi:10.1037/0033-295X.84.2.191.

4. Albert Bandura \& D. H. Schunk. 1981. Cultivating competence, self-efficacy, and intrinsic interest through proximal self-motivation. Journal of Personality and Social Psychology, 41(3), 586-598. doi:10.1037/0022-3514.41.3.586.

5. Albert Bandura. 1982. Self-Efficacy Mechanism in Human Agency. American Psychological Association. Vol. 37, No.2, 122-147.

6. Albert Bandura. 1989. Regulation of cognitive processes through perceived self-efficacy. Developmental Psychology, 25(5), 729-735. doi:10.1037/0012-1649.25.5.729.

7. Albert Bandura. 1998. Health promotion from the perspective of social cognitive theory. Psychology and Health, 13, 623-649.

8. Albert Bandura. 2001. Social Cognitive Theory of Mass Communication. Media Psychology. 3(3), 265-299. 